\title{
ESTIMATION OF PV MODULE PARAMETERS USING GENERALIZED HOPFIELD NEURAL NETWORK
}

\author{
Ranjith Dharmarajan ${ }^{1 *}$, Rajeswari Ramachandran ${ }^{2}$ \\ ${ }^{I} P G$ Scholar, Department of Electrical and Electronics Engineering, Government College of Technology, \\ Coimbatore, TN, India \\ ${ }^{2}$ Associate Professor, Department of Electrical and Electronics Engineering, Government College of Technology, \\ Coimbatore, TN, India \\ *Corresponding author E-Mail ID: ranjithgct17@gmail.com, Mobile: +919790978785.
}

\begin{abstract}
The estimation of solar photovoltaic (PV) system with help of electrical model parameters, such as photon generated current, the diode saturation current, series resistance, shunt resistance, and diode ideality factor, are desirable to predict the real performance characteristics of solar PV under varying environmental conditions. Finally, performance indices, such as PV characteristics curve are estimated for the various solar PV panels using GHNN optimization technique.
\end{abstract}

Keywords: Generalized Hopfield Neural Network (GHNN), Photovoltaic (PV).

\section{INTRODUCTION}

Solar panels harness the sun energy in the form of light and convert the energy into electricity. Although the average consumer might associate solar panels with residential rooftop assemblies, solar panels are available for a wide range of applications, including powering individual gadgets, electronic devices and vehicle batteries.

The reserves of fossil fuels are rapidly decreasing at present due to the increased use of thermal power plants and air pollution associated with the combustion of fossil fuels is increasing. Hence, in the present scenario, there is an urgent need to speed up the research and development of renewable energy technology, especially solar energy, to meet the world energy demand.

The goal of this dissertation is to develop and apply an integrated assessment framework, for one of the sustainable electricity options, solar photovoltaic (PV) technology. In this dissertation different types of photovoltaic modules are considered that are widely manufactured in the market at present, and the future implications of using PV technology in the electricity sector is evaluated.

PV electricity mitigates emissions from thermal power plants to the grid. Inclusion of such monetary benefits from mitigation into the evaluation of the economic performance, PV technology encourage economic sustainability. 


\section{ANALSIS OF SINGLE DIODE PV MODULE}

A single diode model of the solar PV module is have the unknown parameters from figure 2.1, namely $\mathrm{I}_{\mathrm{lg}}, \mathrm{I}_{\mathrm{sat}}, \mathrm{A}, \mathrm{R}_{\mathrm{se}}$, and $\mathrm{R}_{\mathrm{sh}}$. By taking the datasheet information provided by the manufacturer of the PV module at standard test conditions (STCs), the PV module's parameters are estimated.

\subsection{Single Diode Solar PV Module}

A single diode model of the PV module is shown in Figure 2.1. By using the PV module parameters obtained at STCs, the values of the five parameters and the MPP of the PV module can be estimated at any temperature and irradiance condition.

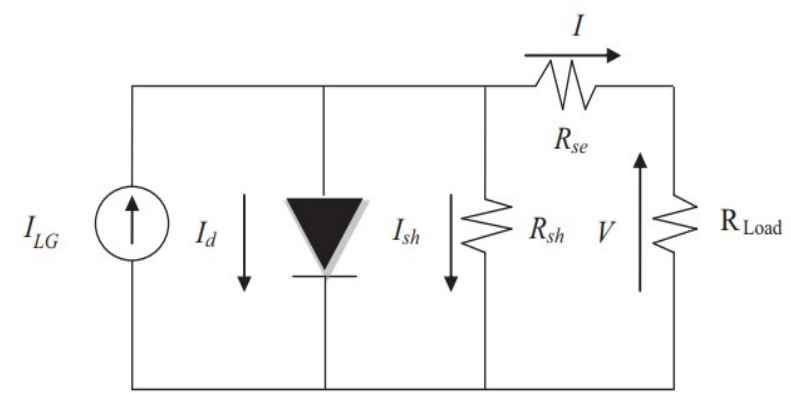

Fig 1. Equivalent circuit of PV module

$$
\mathbf{I}=\mathrm{I}_{\mathrm{lg}}-\mathrm{I}_{\mathrm{gat}}\left[\mathrm{e}\left(\mathrm{V}+\frac{\mathrm{IR}_{\mathrm{ge}}}{\mathrm{N}_{\mathrm{g}} \mathrm{V}_{\mathrm{t}}}\right)-1\right]-\frac{\mathrm{V}+\mathrm{IR}_{\mathrm{ge}}}{\mathrm{R}_{\mathrm{sh}}}
$$

Where,

$\mathrm{I}_{\mathrm{lg}}$ - Light generated current in amps

$\mathrm{N}_{\mathrm{S}}$-Number of solar cells connected in series

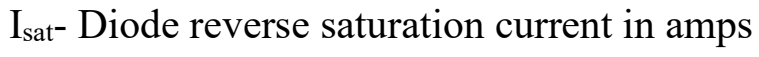

$\mathrm{R}_{\mathrm{se}}-$ Series resistance of solar module in ohms

$\mathrm{R}_{\text {sh-Shunt resistance of solar module in ohms }}$

The thermal voltage of diode, $\mathrm{V}_{\mathrm{t}}$, is expressed as,

$$
\mathrm{V}_{\mathrm{t}}=\mathrm{AkT}_{\mathrm{d}} / \mathrm{q}
$$

Where,

A- Diode ideality factor

$\mathrm{k}$-Boltzmann constant $\left(1.3806 * 10^{\wedge}-23 \mathrm{~J} / \mathrm{K}\right)$

$\mathrm{T}_{\mathrm{c}}$ - PV module temperature (STC) in $\mathrm{K}$

$\mathrm{q}$ - Electronic charge $\left(1.602 * 10^{\wedge}-19 \mathrm{C}\right)$

The important parameters to be noted from the manufacturer's datasheet are short circuit current $\left(\mathrm{I}_{\mathrm{sc}}\right)$, open circuit voltage $\left(\mathrm{V}_{\mathrm{oc}}\right)$, and maximum power point are $\left(\mathrm{V}_{\mathrm{mpp}} \& \mathrm{I}_{\mathrm{mpp}}\right)$. The values at STCs, for which the irradiance $\left(\mathrm{G}_{\mathrm{stc}}\right)$ is $1000 \mathrm{~W} / \mathrm{m}^{2}$ and the cell temperature $\left(\mathrm{T}_{\text {stc }}\right)$ is $25 \circ \mathrm{C}$. The 
data sheet also provides temperature coefficients for short circuit current (ki), open circuit voltage $(\mathrm{kv})$, and maximum power (kp).

\subsubsection{Extraction of PV Module Parameters}

The five unknown parameters are to be estimate of the PV module from the nonlinear equation (1), five independent equations are required. The first three equations, (4), (7), and (9), are derived from Eq. (1) by applying short circuit, open circuit, and MPP conditions. The remaining two equations, (12) and (14), are derived by differentiating the values of power and current with respect to voltage.

\subsection{SHORT CIRCUIT CONDITION (SCC)}

Under the short circuit condition,

$$
I_{g c}=I_{l g} I_{g a t}\left[e\left(\frac{I_{g c} R_{g h}}{N_{g} V_{t}}\right)-1\right]-\left(\frac{I_{g e} R_{g e}}{R_{g h}}\right)
$$

After some approximation, the light generated current $\left(\mathrm{I}_{\mathrm{lg}}\right)$ can be written as

$$
I_{1 \mathrm{~g}}=\frac{I_{s e}\left(R_{s e}+R_{s h}\right)}{R_{s h}}
$$

\subsection{OPEN CIRCUIT CONDITION (OCC)}

Under the open circuit condition,

$$
0=I_{l_{g}}-I_{g a t} e\left(\frac{V_{o c}}{N_{g} V_{t}}\right)-\frac{V_{o c}}{R_{g h}}
$$

This equation is rearranged and the reverse saturation current is expressed as

$$
I_{s a t}=\left(I_{l g}-\frac{V_{o c}}{R_{s h}}\right) e\left(-\frac{V_{o c}}{N_{s} V_{t}}\right)
$$

Substituting $\mathrm{I}_{\mathrm{g}}$ from short circuit, the saturation current can be derived as,

$$
I_{\text {sat }}=\left(\frac{I_{s e}\left(R_{s e}+R_{s h}\right)-V_{0 c}}{R_{s h}}\right) e\left(-\frac{V_{0 c}}{N_{S} V_{t}}\right)
$$

\subsection{MAXIMUM POWER POINT (MPP) CONDITION}

The maximum power point calculation are as follows:

$$
I_{m p p}=I_{\text {lg }}-I_{s a t}\left[e\left(\frac{V_{m p p}+I_{m p p} R_{s e}}{N_{g} V_{t}}\right)-1\right]-\frac{V_{m p p}+I_{m p p} R_{s e}}{R_{s h}}
$$

Inserting $I_{l g}$ and $I_{s a t}$ into this equation, we get the equation as

$$
\begin{aligned}
I_{m p p}= & \left(\frac{I_{s c}\left(R_{s e}+R_{s h}\right)-\left(V_{m p p}+I_{m p p} R_{s e}\right)}{R s h}\right) \\
& -\left(\frac{I_{s c}\left(R_{s e}+R_{s h}\right)-V_{o c}}{R_{s h}}\right) e\left(\frac{V_{m p p}+I_{m p p} R_{s e}-V_{o c}}{N_{s} V_{t}}\right)
\end{aligned}
$$




\subsection{CALCULATION OF INITIAL VALUES}

To select the initial value for $R_{s e}$ and $R_{s h}$ the following equations are considered. Because of high sensitivity, the numerical methods may fail to converge due to improper selection of the initial value of the PV module parameters.

$$
\begin{aligned}
& R_{s e} \text { initial }=\left(\frac{V_{0 c}}{I_{s c}}\right)-\left(\frac{V_{m p p}}{I_{m p p}}\right) \\
& R_{s h} \text { initial }=V_{m p p} /\left(I_{s c}-I_{m p p}\right)
\end{aligned}
$$

The $V_{t}, R_{s e}$ and $R_{s h}$ are given by the equations,

$$
\begin{gathered}
V_{t}=\frac{V_{m p p}+I_{m p p} R_{s e}-V_{o c}}{\left(N_{s} \ln \left(\frac{I_{s c}\left(R_{s e}+R_{s h}\right)-V_{o c}}{\left(I_{s c}-I_{m p p}\right)\left(R_{s e}+R_{s h}\right)-V_{m p p}}\right)\right.} \\
R_{s e}=\frac{V_{o c}-V_{m p p}+N_{s} V_{t} s}{I_{m p p}}
\end{gathered}
$$

Where,

$$
\begin{aligned}
& S=\ln \left(\frac{\left(N_{g} V_{t}\left(I_{m p p}\left(R_{s g}+R_{s h}\right)-V_{m p p}\right)\right.}{I_{s c} V_{m p p}\left(R_{s e} R_{s h}\right)+I_{m p p} R_{s e}\left(V_{o c}-I_{s c} R_{s e}-I_{s c} R_{s h}\right)-V_{m p p} V_{o c}}\right)
\end{aligned}
$$

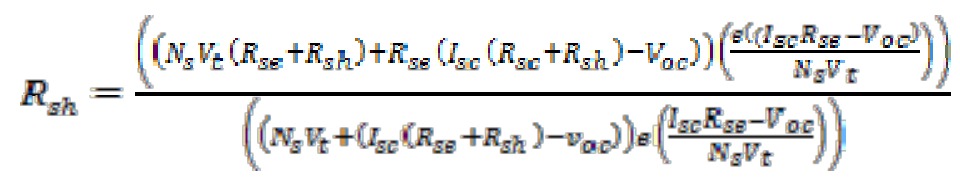

The PV module parameters $I_{l g^{n}} I_{s a t}, A, R_{s e}$ and $R_{s h}$ can be obtained by open and short circuit test. First, these three equations are solved by GHNN and the values of $\mathrm{V}_{\mathrm{t}}, R_{g g}, R_{s h}$ are obtained

The remaining parameters are obtained from short and open circuit test using the values of $V_{t}, R_{s e}, R_{s h}$.

\subsection{EFFECT OF VARYING IRRADIANCE AND TEMPERATURE}

The light generated current and short circuit current are directly proportional to irradiance and depends on temperature.

$$
\begin{aligned}
& I_{l_{B}(G)}=I_{l_{g}(s t c)} \times \frac{G}{G_{s t c}} \\
& I_{s c(G)}=I_{s c(s t c)} \times \frac{G}{G_{s t c}}
\end{aligned}
$$

Where,

$G_{\text {ste }}$ - Irradiance at STC $\left(\mathrm{w} / \mathrm{m}^{2}\right)$

$\mathrm{G}$ - Irradiance under given operating condition 
The open circuit voltage equation can be described as the function of irradiance as given by and this equation is solved by Newton Raphson.

$$
V_{o c(G)}=N_{s} V_{t} \ln \left(\frac{I_{\lg (G)} R_{g h 2}-V_{o c(G)}}{I_{g G t} R_{s h}}\right)
$$

The short circuit current and open circuit voltage can be evaluated for the given operating temperature as given by

$$
\begin{aligned}
& I_{s c(T)}=I_{s c(s t c)}+k_{i}\left(T_{c}-T_{s t c}\right) \\
& V_{o c(T)}=V_{o c(s t c)}+K_{v}\left(T_{c}-T_{s t c}\right)
\end{aligned}
$$

Where,

$T_{\text {ste }}-$ Cell temperature at STC, $\mathrm{K}$.

by,

The light generated current can be determined as a function of temperature and is given

$$
I_{\mathrm{lg}(T)}=I_{s c(T)}\left(R_{s e}+R_{s h}\right) /\left(R_{s h}\right)
$$

The short circuit current, open circuit voltage and light generated current can be estimated at any temperature and irradiance using the following three equations.

$$
\begin{gathered}
I_{l_{g}(G T)}=\left(I_{l_{g}(s t c)}+k_{i}\left(T_{c}-T_{s t c}\right)\right)\left(\frac{G}{G_{s t c}}\right) \\
I_{s c(G T)}=\left(I_{s c(s t c)}+k_{i}\left(T_{c}-T_{s t c}\right)\right)\left(\frac{G}{G_{s t c}}\right) \\
V_{o c(G T)}=V_{o v(G)}+K_{v}\left(T_{c}-T_{s t c}\right)
\end{gathered}
$$

The thermal voltage $V_{t}$ is directly proportional to PV panel cell temperature and is given by,

$$
V_{t(T)}=V_{t(s t c)}\left(\frac{T}{T_{s t c}}\right)
$$

The diode reverse saturation current, which is a function of irradiance and temperature can be calculated from the equation,

$$
I_{s a t(G T)}=\frac{I_{S C(G)}\left(R_{S B}+R_{S h}\right)-V_{O C}(G T)}{R_{S h}} e\left(-\frac{V_{0 C}(G T)}{N_{S} V_{t}(T)}\right)
$$

\subsection{ESTIMATION OF MAXIMUM POWER POINT}

The proper initial values of $V_{m p p}$ and $I_{m p p}$ should be chosen to estimate the accurate MPP by using the well-known values of $V_{o c}$ amd $I_{s c}$ under given operating conditions. Under varying irradiance and temperature, $\boldsymbol{V}_{t(G T)}, R_{g e(G T)}$ and $R_{s h(G T)}$ are obtained by using the estimated parameters of the PV module such as $I_{\lg ,} I_{\text {sat }} A_{y} R_{s g}$, and $R_{s h}$ at STC's. 

conditions.

In general, the PV module parameters change considerably due to various environmental

$$
R_{s e(G T)}=R_{s e(s t c)}\left(\frac{I_{\operatorname{Lg}(G T)}}{I_{\lg (s t e)}}\right)
$$

The value of shunt resistance is considered a constant in [10] but the value of shunt resistance of the PV module is indirectly proportional to the short circuit current under varying operating conditions in this paper, anew equation is introduced for the shunt resistance variation with respect to temperature and irradiance and is expressed as

$$
R_{\operatorname{sh}(G T)}=R_{s h(s t c)}\left(\frac{I_{s e(s t c)}}{\left.I_{\text {sel }(G T)}\right)}\right.
$$

In order to find MPP, The maximum voltage is found as a function of temperature and irradiance and is given by,

$$
V_{m p p}=V_{o c(G T)}-I_{m p p} R_{s e(G T)}+N_{S} V_{t(G T)} U
$$

Where,

$$
U=\ln \left(\frac{\left[\left(\left(I_{s e(G T)}-I_{m p p}\right)\left(R_{s e(G T)}+R_{s h(G T)}\right)-V_{m p p}\right)\right]}{I_{s e(G T)}\left(R_{s e(G T)}+R_{s h(G T)}-V_{\operatorname{sol}(G T)}\right)}\right)
$$

The maximum current serves as a function of temperature and irradiance and is given by,

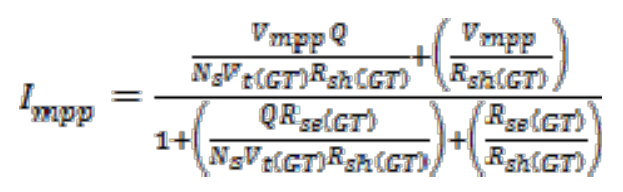

Where,

$$
Q=\left(I_{s c(G T)}\left(R_{s c(G T)}+R_{s h(G T)}\right)-V_{a c(G T)}\right) e\left(\frac{\left.V_{m p p}+I_{m p p} R_{s e(G T)}-V_{o c(G T)}\right)}{N_{g} V_{t(G T)}}\right.
$$

These three equations can be solved using the Newton Raphson method and Generalised Hopfield Neural Network method. In these two method the error value is taken as the $1 \times 10 \mathrm{e}-10$. These are all the mathematical modelling of the $80 \mathrm{~W}$ PV module that can be used for extracting the five parameters and finding the maximum power point of the prescribed PV module.

\section{Generalized Hopfield Neural Network}

The continuous time single layer feedback networks are called "gradient type networks" in which time is assumed a continuous variable. Gradient type neural networks are the Generalized Hopfield Neural Networks (GHNN) in which the computational energy decreases continuously with time. The evolution of the system is in the general direction of the negative gradient of the energy function. The generalized electrical architecture of the GHNN is shown as in Figure.3.1. 


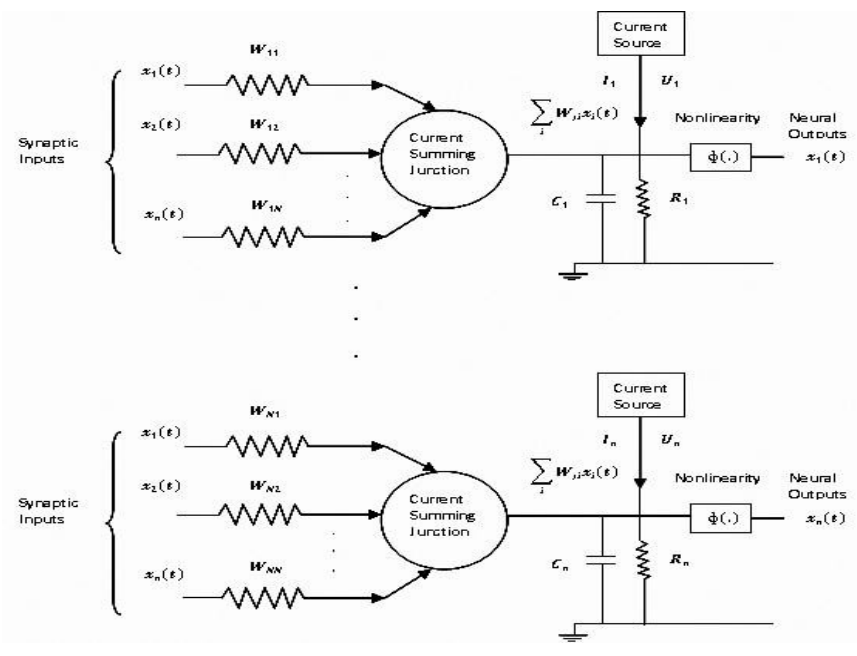

Figure.3.1 Generalized Architecture of GHNN

It consisting of an interconnection of $n$ ' neurons, each one of which is assumed to have the same mathematical model described in equations (1) and (2). Where $R_{j}$ represents leakage resistance, $C_{j}$ represents leakage capacitance and $\varphi$ (.) represents activation function. In physical terms, the synaptic weights $W_{j 1}, W_{j 2}, \ldots W_{j n}$ represent conductance's, and the respective inputs $x_{1}(t), x_{2}(t), \ldots, x_{n}(t)$ represent potentials; $n$ is the number of inputs. These inputs are applied to a current summing junction characterized by low input resistance, unity current gain and high output resistance. It thus acts as a summing node for the input currents. In the generalized Hopfield neural network the inputs to each neuron of the network not only come from the outputs of other neurons but also from the product of several outputs. The total current flowing toward the input node of the nonlinear element(activation function) in Figure. 2 is therefore where the first term is due to the stimuli $x_{1}(t), x_{2}(t), \ldots, x_{n}(t)$ acting on the synaptic weights (conductance) $W_{j 1}$, $W_{j 2}, \ldots W_{j n}$ respectively, and the second term is due to the current source $I_{j}$ representing an externally applied bias.

$$
\sum_{i=1}^{N} W_{j i} x_{i}(t)+I_{j}
$$

Let $u_{j(t)}$ denote the induced local field at the input of the nonlinear activation function. We may then express the total current flowing away from the input node of the nonlinear element as follows:

$$
\frac{u_{j\left(t_{2}\right)}}{R_{j}}+C_{j} \frac{d u_{j\left(t_{1}\right)}}{d t}
$$

Where the first term is due to the leakage resistance $R_{j}$ and the second term is due to leakage capacitance $C_{j}$. From Kirchhoff's current law, we know that the total current flowing toward any node of an electrical circuit is zero. By applying Kirchhoff's current law to the input node of the nonlinearity. We may define the dynamics of the network by the following system of coupled first-order differential equations by ignoring interneuron propagation time delays.

$$
. C_{j} \frac{d u_{j(t)}}{d t}=-\frac{u_{j(t)}}{R_{j}}+\sum_{i=1}^{N} W_{j i} x_{i}(t)+I_{j}{ }^{4}
$$

An assumption is made that the activation function relating the output $x_{j(\mathrm{t})}$ of neuron ,j' to its induced local field $u_{j(t)}$ is a continuous function and therefore differentiable. A commonly used activation function is the logistic function. 


$$
\varphi\left(\mathbf{u}_{j}\right)=\frac{1}{1+\exp \left(-u_{j}\right)} \quad \mathrm{j}=1,2, \ldots \mathrm{n}
$$

The energy function for the proposed model is given by

$$
E=\left(\sum_{i} \int_{0}^{x_{i} \varphi^{-1}(s)} \frac{s_{i}}{R_{i}} d s \sum_{i} \sum_{j} W_{i j} f_{i j}\left(x_{1}, x_{2, j=} x_{N}\right) x_{i}+\sum I_{i} x_{i}\right)
$$

By using conventional methodology one can see that the derivative for the proposed energy function is always less than or equal to zero, i.e. $d E / d t<0$ and energy of the system is thus bounded.

\subsection{Application of GHNN to the solution of nonlinear equations}

Let us consider a set of nonlinear algebraic equations given below:

$$
\begin{aligned}
& \mathrm{f}_{1}\left(\mathrm{x}_{1}, \mathrm{x}_{2} \ldots . . \mathrm{x}_{\mathrm{j}} \ldots . \mathrm{x}_{\mathrm{n}}\right)=\mathrm{P}_{1} \\
& \mathrm{f}_{2}\left(\mathrm{x}_{1}, \mathrm{x}_{2} \ldots ., \mathrm{x}_{\mathrm{j}} \ldots . \mathrm{x}_{\mathrm{n}}\right)=\mathrm{P}_{2} \\
& . \mathrm{fj}\left(\mathrm{x}_{1}, \mathrm{x}_{2} \ldots ., \mathrm{x}_{\mathrm{j}} \ldots . \mathrm{x}_{\mathrm{n}}\right)=\mathrm{P}_{\mathrm{j}} \\
& \mathrm{f}_{\mathrm{n}}\left(\mathrm{x}_{1}, \mathrm{x}_{2} \ldots ., \mathrm{x}_{\mathrm{j}} \ldots . \mathrm{x}_{\mathrm{n}}\right)=\mathrm{P}_{\mathrm{n}}
\end{aligned}
$$

In the above equations $f($.$) is a function of variables \mathrm{x}_{1}, \mathrm{x}_{2} \ldots \ldots, \mathrm{x}_{\mathrm{j}} \ldots . . \mathrm{x}_{\mathrm{n}} \in \Re$ and $\epsilon \Re$ is a real constant. Our objective is to find the values for variables $\mathrm{x}_{1}, \mathrm{X}_{2} \ldots . ., \mathrm{X}_{\mathrm{j}} \ldots . . \mathrm{x}_{\mathrm{n}}$ such that it satisfies the equation (3.6). To obtain the solution using proposed approach an energy function has to be formulated. The energy function for the above set of equations is derived as follows:

$$
E=\sum_{j}^{n}\left(\left(g_{j}(\cdot)\right)^{2}\right.
$$

Where,

$$
g_{j}(.)=\left(f_{j}\left(x_{1}, x_{2}, \ldots, x_{j} \ldots x_{n}\right)-P_{j}\right)
$$

Equations (3.7) and (3.8) have been used for designing the proposed network. The number of neurons in network is equal to the number of variables whose value is to be determined. In the given problem we have ' $n$ ' number of variables and hence the network should have ' $n$ ' number of neurons. The network dynamics are governed by the following differential equations:

$$
\begin{aligned}
& \frac{d u_{j}}{d t}=-\frac{d E}{d x_{j}} \\
& x_{j}=\varphi u, j=1 \ldots n
\end{aligned}
$$

Where, $\mathrm{u}_{j}$ is the net input to the $j^{\text {th }}$ neuron in the network and is its output. In this application the function $\varphi\left(\right.$.) linear input, output transfer function for the $j^{\text {th }}$ neuron. Calculating the partial derivatives of equation (3.8) with respect to unknown variables $x_{1}, 2, \ldots, x_{j} \ldots x_{n}$ and collecting the terms of identical order will result in Hopfield equations like form. The coefficients and constants in the available expression give the weights and bias values for the network respectively. 


\subsection{APPLICATION OF GHNN TO ESTIMATION PV MODULE PARAMETRES STC AND VARYING IRRADIENCE AND TEMPERATURE}

Single diode PV module equivalent circuit shown in fig 2.1. The Non Linear equation are derived from the equivalent circuit. From help of these Non-linear equations estimate the unknown parameters of the PV module using single diode equivalent circuit of Diode ideality factor $(A)$, Shunt Resistor $\left(R_{s h}\right)$, Series Resistor $\left(R_{s e}\right)$, Light generated current $\left(I_{L G}\right)$ and Saturation current $\left(\mathrm{I}_{\mathrm{sat}}\right)$.

Only three parameters are need to calculate by using GHNN and remaining two parameters are related to each other. Form the Energy Function for taking the equations (12),(13) \& (14) and separated into variable and constants. Here variables are $V_{t}, R_{s h} \& R_{s e}$ as follows $x_{1}, x_{2}$ $\& \mathrm{X}_{3}$ constants are Data sheet values of the solar panel that is Voc, Isc, Vmpp, Impp and Ns.

$$
E=-0.5\left(x_{1}{ }^{2}+x_{2}{ }^{2}+x_{3}{ }^{3}\right)
$$

Where, $\mathrm{x}_{1}=\mathrm{R}_{\mathrm{se}} ; \mathrm{x}_{2}=\mathrm{R}_{\mathrm{sh}} ; \mathrm{X}_{3}=\mathrm{V}_{\mathrm{t}}$

The differential equation governing the performance of PV module is calculated using energy function and is given as follows:

$$
\begin{aligned}
& \frac{d x_{1}}{d t}=-\frac{\partial E}{\partial x_{1}} \\
& \frac{d x_{2}}{d t}=-\frac{\partial E}{\partial x_{2}} \\
& \frac{d x_{3}}{d t}=-\frac{\partial E}{\partial x_{3}}
\end{aligned}
$$

After this getting three differential equations with respect to corresponding variables of the Energy function. By using ODE solver for solving these three equations we get the value of the variables are $V_{t}, R_{s h} \& R_{s e}$. Using these three values will help to find the $A, I_{L G} \& I_{\text {sat. }}$

The parameters of PV module are namely $I_{\mathrm{lg}}, \mathrm{I}_{\mathrm{sat}}, \mathrm{A}, \mathrm{R}_{\mathrm{se}}$, and $\mathrm{R}_{\mathrm{sh}}$. By taking the datasheet information Table 1, provided by the manufacturer of the PV module at standard test conditions (STCs), the PV module's parameters are estimated. By using the PV module parameters obtained at STCs, the values of the five parameters and the MPP of the PV module can be estimated at any temperature and irradiance condition.

\section{ALGORITHM}

Step 1: Assign the input values for $I_{S C}, V_{O C}, V_{M P P}$ IMPP \& $N_{S}$.

Step 2: Form the Energy function for PV module.

Step 3: Differentiate the Energy function with respect to variables.

Step 4: Solve the differentiated equations with help of ODE solver with proper initial values of the variables. 


\section{Flow chart}

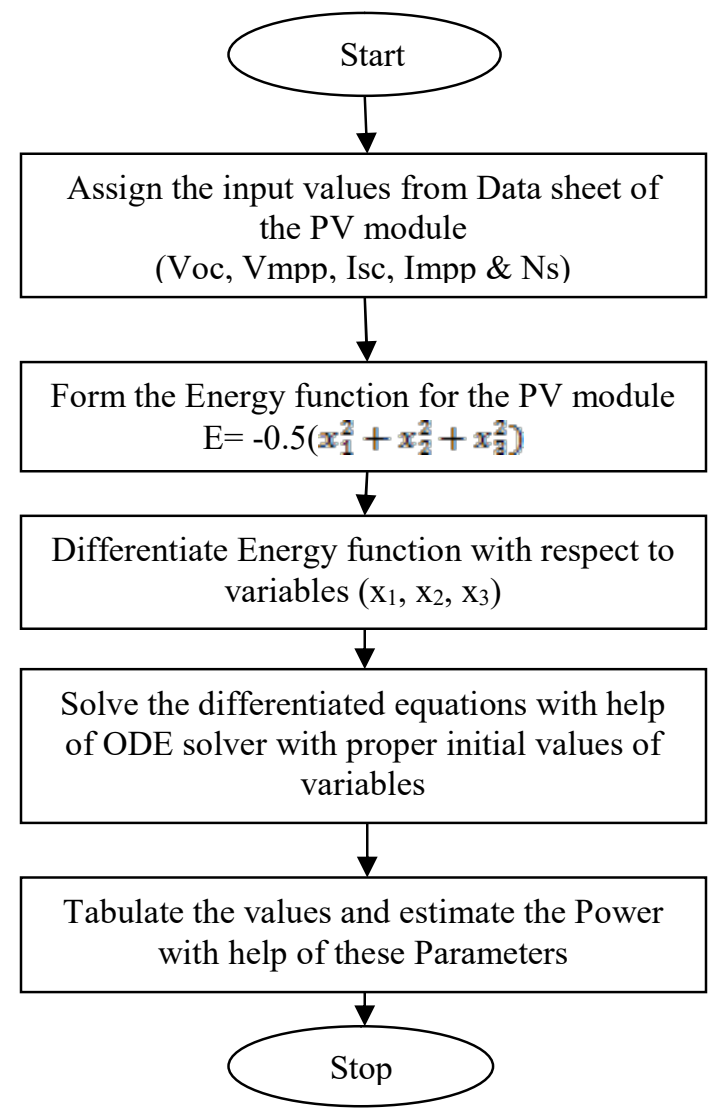

Figure. 3.2 Flowchart for the GHNN method

These values are given at STCs, for which the irradiance (Gstc) is $1000 \mathrm{~W} / \mathrm{m}^{2}$ and the cell temperature (Tstc) is $25 \circ \mathrm{C}$ as followed by flow chart figure 3.2 .

Table 1. Datasheet of PV modules

\begin{tabular}{|l|l|l|l|l|l|}
\hline \multirow{2}{*}{\multicolumn{1}{|c|}{ PV Module }} & \multicolumn{5}{c|}{ Datasheet values } \\
\cline { 2 - 6 } & $\mathbf{I}_{\mathbf{s c}}(\mathbf{A})$ & $\mathbf{I}_{\mathbf{m p p}}(\mathbf{A})$ & $\mathbf{V}_{\mathbf{o c}}(\mathbf{V})$ & $\mathbf{V}_{\mathbf{m p p}}(\mathbf{V})$ & $\mathbf{N}_{\mathbf{s}}$ \\
\hline KD245GX & 8.91 & 8.23 & 36.9 & 29.80 & 60 \\
\hline U5-80 & 5.21 & 4.58 & 21.34 & 17.46 & 36 \\
\hline Shell SP70 & 4.7 & 4.25 & 21.4 & 16.5 & 36 \\
\hline
\end{tabular}

Table 2. Estimated parameters for various PV modules at STCs

\begin{tabular}{|l|c|c|c|c|c|}
\hline \multirow{2}{*}{ PV Module } & \multicolumn{5}{|c|}{ Estimated parameters } \\
\cline { 2 - 6 } & $\mathbf{A}$ & $\mathbf{R}_{\text {se }}(\mathbf{\Omega})$ & $\mathbf{R}_{\text {sh( } \mathbf{(})}$ & $\mathbf{I}_{\text {Ig }}(\mathbf{A})$ & $I_{\text {sat }}(\mathbf{A})$ \\
\hline KD245GX & 1.429 & 0.1574 & 23.235 & 8.9123 & $4.67 \mathrm{E}-07$ \\
\hline U5-80 & 1.6043 & 0.0092 & 66.63 & 5.2107 & $2.76 \mathrm{E}-06$ \\
\hline Shell SP70 & 1.5536 & 0.3235 & 321.2234 & 4.7047 & $1.57 \mathrm{E}-06$ \\
\hline
\end{tabular}

The parameters are estimated using GHNN optimization technique in standard test conditions (STCs) and tabulated different PV modules of 250W solar panel KD245GX and 80W solar panels of U5-80, Shell SP70. 
The GHNN method for estimated five parameters of PV modules with help of equations (12), (13) \& (13) in STCs are shown in Table 2.

Table 3. Estimated parameters for various PV modules at varying irradiance and temperature

\begin{tabular}{|c|c|c|c|c|c|c|c|c|c|c|}
\hline 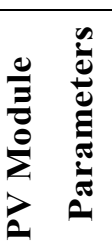 & $\begin{array}{c}G \\
\left(W / \mathbf{m}^{2}\right)\end{array}$ & $\begin{array}{c}\text { Tc } \\
\left({ }^{\circ} \mathrm{C}\right)\end{array}$ & $\mathbf{A}$ & $\begin{array}{l}\text { Rse } \\
(\Omega)\end{array}$ & $\begin{array}{l}\text { Rsh } \\
(\Omega)\end{array}$ & $\begin{array}{l}\mathbf{I}_{\mathbf{L G}} \\
\text { (A) }\end{array}$ & $\begin{array}{l}\text { Isat } \\
\text { (A) }\end{array}$ & $\begin{array}{c}\text { Vmpp } \\
(\mathbf{V})\end{array}$ & $\begin{array}{c}\text { Impp } \\
\text { (A) }\end{array}$ & $\begin{array}{c}\text { Pmpp } \\
(W)\end{array}$ \\
\hline \multirow{6}{*}{ 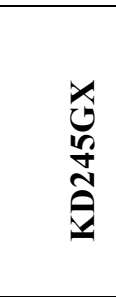 } & 600 & 25 & 1.4797 & 0.0944 & $1.04 \mathrm{E}+03$ & 5.3465 & $8.56 \mathrm{E}-07$ & 29.2352 & 4.9292 & 144.1015 \\
\hline & 800 & 25 & 1.4524 & 0.1259 & 779.0438 & 7.1292 & 6.41E-07 & 28.9245 & 6.5614 & 194.1068 \\
\hline & 1000 & 30 & 1.4093 & 0.1574 & 623.2331 & 8.9123 & $5.15 \mathrm{E}-07$ & 29.6772 & 8.2255 & 244.1471 \\
\hline & 1000 & 50 & 1.322 & 0.1574 & 623.2256 & 8.9124 & $5.15 \mathrm{E}-07$ & 29.6745 & 8.2255 & 244.1286 \\
\hline & 1000 & 70 & 1.2449 & 0.1574 & 623.2182 & 8.9125 & 5.16E-07 & 29.6717 & 8.2255 & 244.1093 \\
\hline & 1100 & 25 & 1.4329 & 0.1731 & 566.5773 & 9.804 & $5.66 \mathrm{E}-07$ & 29.4451 & 9.0371 & 266.1273 \\
\hline \multirow{5}{*}{$\begin{array}{l}\frac{P}{2} \\
\frac{\hat{n}}{\bar{d}} \\
\frac{\bar{d}}{n}\end{array}$} & 200 & 25 & 1.7483 & 0.0647 & $1.61 \mathrm{E}+03$ & 0.94 & 7.17E-06 & 15.1603 & 0.8428 & 12.7765 \\
\hline & 400 & 25 & 1.7483 & 0.1294 & 803.0585 & 1.8803 & $1.43 \mathrm{E}-05$ & 15.0481 & 1.6802 & 25.2812 \\
\hline & 600 & 25 & 1.7483 & 0.1941 & 535.3723 & 2.8238 & $2.15 \mathrm{E}-05$ & 14.8269 & 2.5123 & 37.2838 \\
\hline & 800 & 25 & 1.7483 & 0.2588 & 401.5293 & 3.7624 & $2.87 \mathrm{E}-05$ & 14.5227 & 3.3335 & 48.4109 \\
\hline & 1000 & 25 & 1.7483 & 0.3235 & 321.2234 & 4.7047 & $3.59 \mathrm{E}-05$ & 14.1407 & 4.1391 & 58.5244 \\
\hline \multirow{3}{*}{$\begin{array}{l}8 \\
\infty \\
1 \\
0\end{array}$} & 351 & 35.7 & 1.684 & 0.0032 & 189.3624 & 1.8332 & $9.03 \mathrm{E}-06$ & 15.7181 & 1.5952 & 25.0768 \\
\hline & 426 & 42 & 1.6503 & 0.0039 & 155.7984 & 2.2283 & $1.10 \mathrm{E}-05$ & 15.7143 & 1.9384 & 30.4676 \\
\hline & 568 & 44 & 1.6399 & 0.0052 & 116.7952 & 2.9723 & $1.47 \mathrm{E}-05$ & 15.7079 & 2.5856 & 40.6229 \\
\hline
\end{tabular}

The light generated current and short circuit current are directly proportional to irradiance and also depend on temperature. The unknown parameters of PV module namely $I_{\mathrm{lg}}, \mathrm{I}_{\mathrm{sat}}, \mathrm{A}, \mathrm{R}_{\mathrm{se}}$, and $\mathrm{R}_{\text {sh., }}$ can be estimated at any temperature and irradiance condition.

PV modules of 250W solar panel KD245GX and 80W solar panels of U5-80, Shell SP70 are taken estimated PV panel equivalent circuit parameters at any temperature and irradiance conditions using GHNN optimization technique are shown in Table 3.

\section{CONCLUSION}

In this work, the following PV modules are taken for estimate the five unknown parameters of KD245GX, U5-80 and Shell SP70. The GHNN optimization technique is used to estimate the five unknown parameters of the PV modules at STCs. Here, good convergence is achieved in the GHNN method during MATLAB coding, due to the selection of appropriate initial values from the series and shunt resistance equations. The Energy function is used to extract the MPP at different environmental conditions by considering the varying nature of shunt resistance, series resistance, and ideality factor. In particular, through the proposed equations of shunt resistance and ideality factor of the PV model, accurate MPP value is obtained. For a wide range of operating conditions, the MPP and the five unknown parameters of various PV modules are estimated.

\section{REFERENCES}

[1] Rauschenbach HS, 1976, "Solar Cell Array Design Handbook", Vol. 1, JPL, Pasadena, CA, USA: Van Nostrand Reinhold. 
[2] Celik AN, Acikgoz N, 2007, "Modelling and experimental verification of the operating current of mono-crystalline photovoltaic modules using four and five parameter models", Appl Energ; 84: $1-15$.

[3] Alonso-Garcia MC, Ruiz JM, 2006, "Analysis and modelling the reverse characteristic of photovoltaic cells", Sol Energ Mat Sol C; 90: 1105-1120.

[4] Carrero C, Ramirez D, Rodr'1guez A, Platero CA, 2011, "Accurate and fast convergence method for parameter estimation of PV generators based on three main points of the I-V curve", Renew Energ; 36: 2972-2977.

[5] Zhu XG, Fu ZH, Long XM, Li X, 2011, "Sensitivity analysis and more accurate solution of photovoltaic solar cell parameters", Sol Energy; 85: 393-403.

[6] Saloux E, Teyssedou A, Sorin M, 2011, "Explicit model of photovoltaic panels to determine voltages and currents at the maximum power point", Sol Energy; 85: 713-722.

[7] Cotfas D, Cotfas P, Kaplanis S, Ursutiu D, 2008, "Results on series and shunt resistances in a c-Si PV cell, Comparison using existing methods and a new one", J Optoelectron Adv M ; 10: 3124-3130.

[8] Ly Diallo H, Dieng B, Ly I, Dione MM, Ndiaye M, Lemrabott OH, Bako ZN, Wereme A, Sissoko G, 2012, "Determination of the recombination and electrical parameters of a vertical multi junction silicon solar cell”, Res J Appl Sci Eng Technol; 4: 2626-2631.

[9] Chatterjee A, Keyhani A, Kapoor D, 2011, "Identification of photovoltaic source models", IEEE T Energy Conver; 26: 883-889.

[10] Kulaksiz AA, 2013, "ANFIS-based estimation of PV module equivalent parameters: application to a stand-alone PV system with MPPT controller", Turk J Elec Eng \& Comp Sci 2013; 21: 2127-2140.

[11] De Soto W, Klein SA, Beckman WA, 2006, "Improvement and validation of a model for photovoltaic array performance", Sol Energy; 80: 78-88.

[12] Anand.B, Balasubramonian.M, 2014, "Generalized Hopfield Neural Network Based SHEPWM in A Single Phase Inverter”, IJAIST; Vol.22, No.22, pp. 31-37. 